\title{
Out of pocket expenditure to deliver at public health facilities in India: a cross sectional analysis
}

\author{
Anns Issac, Susmita Chatterjee, Aradhana Srivastava and Sanghita Bhattacharyya*
}

\begin{abstract}
Background: To expand access to safe deliveries, some developing countries have initiated demand-side financing schemes promoting institutional delivery. In the context of conditional cash incentive scheme and free maternity care in public health facilities in India, studies have highlighted high out of pocket expenditure (OOPE) of Indian families for delivery and maternity care. In this context the study assesses the components of OOPE that women incurred while accessing maternity care in public health facilities in Uttar Pradesh, India. It also assesses the determinants of OOPE and the level of maternal satisfaction while accessing care from these facilities.

Method: It is a cross-sectional analysis of 558 recently delivered women who have delivered at four public health facilities in Uttar Pradesh, India. All OOPE related information was collected through interviews using structured pre-tested questionnaires. Frequencies, Mann-Whitney test and categorical regression were used for data reduction.

Results: The analysis showed that the median OOPE was INR 700 (US\$ 11.48) which varied between INR 680 (US\$ 11.15) for normal delivery and INR 970 (US\$ 15.9) for complicated cases. Tips for getting services (consisting of gifts and tips for services) with a median value of INR 320 (US\$ 5.25) contributed to the major share in OOPE. Women from households with income more than INR 4000 (US\$ 65.57) per month, general castes, primi-gravida, complicated delivery and those not accompanied by community health workers incurred higher OOPE. The significant predictors for high OOPE were caste (General Vs. OBC, SC/ST), type of delivery (Complicated Vs. Normal), and presence of ASHA (No Vs. Yes). OOPE while accessing care for delivery was one among the least satisfactory items and $76 \%$ women expressed their dissatisfaction.
\end{abstract}

Conclusion: Even though services at the public health facilities in India are supposed to be provided free of cost, it is actually not free, and the women in this study paid almost half of their mandated cash incentives to obtain delivery care.

Keywords: Out of pocket expenditure, Tips for getting services, Delivery care, Public health facilities, India

Abbreviations: ASHA, Accredited social health activist; JSSK, Janani Shishu Suraksha Karyakram; JSY, Janani Suraksha Yojana; OBC, Other backward caste; OOPE, Out of pocket expenditure; SC/ST, Scheduled caste/scheduled tribe

\footnotetext{
*Correspondence: sanghita@phfi.org

Public Health Foundation of India, Plot no. 47, Sector 44 Institutional Area,

Gurgaon 122002, Haryana, India
} 


\section{Plain English summary}

Some developing countries have introduced promotional schemes for institutional delivery so that they could improve women's access to safe delivery care. In India, there is a scheme, titled Janani Shishu Suraksha Karyakram, which entitles women to free delivery care at public health facilities. However, a few studies suggested that the women had to pay for obtaining services even at the public health facilities. To understand the different components of cost of care, the present study conducted a survey of 558 women who had delivered at public health facilities in two districts of Uttar Pradesh.

The majority (97\%) of the women paid from their pocket for services, and the median cost was INR 700 (US\$ 11.48); this was half the cash incentive provided by the government scheme. This amount varied between INR 680 (US\$ 11.15) for normal delivery and INR 970 (US\$ 15.9) for complicated cases. The major component was tips for getting services (consisting of gifts and tips for services) with a median value of INR 320 (US\$ 5.25). Women from higher income households (more than INR 4000 (US\$ 65.57)/ month), general castes, those who were the first-time mothers, complicated delivery and those not accompanied by community health workers paid more.

The study concludes that the care from the public health facility is in fact not free, and this can discourage women opting for institutional delivery.

\section{Background}

Developing countries suffer from unacceptably high rates of maternal and infant mortality, accounting for 99\% of global maternal deaths [1]. One of the primary reasons for this is the lack of access to safe deliveries, especially among the poor, where healthcare access often imposes a considerable financial burden on families [2]. To expand access to safe deliveries and reduce the risk of maternal and newborn emergencies, some developing countries have initiated demand-side financing schemes to promote institutional delivery. Among the South Asian countries, Nepal has the cash incentive scheme and Bangladesh and Pakistan have voucher schemes [3]. Several studies from low and middle-income countries have shown that the cost of care is a major determinant of maternal care utilization and satisfaction with institutional delivery care $[4,5]$. Significant associations of cost or affordability of care with maternal satisfaction and the utilization of care in institutional births were found in studies in Nigeria, Zambia, Kenya, Egypt, India, Gambia and Ghana [6-13].

With a high maternal mortality ratio of 178, saving maternal and newborn lives is a key concern in India [14]. The Government of India launched the conditional cash transfer scheme of Janani Suraksha Yojana (JSY) in 2005 to promote institutional deliveries, offering a monetary incentive of INR 1400 (US\$22.95) ${ }^{1}$ to women delivering in public or accredited private facilities. The program is supported by the Accredited Social Health Activist (ASHA), a community health worker who motivates women to deliver at public facilities and also accompanies them to the facilities [15]. The delivery services, including medicines, tests and food are provided free of cost to encourage women to opt for institutional delivery and offset their related expenditure burden [16]. Later, JSY was modified to Janani Shishu Suraksha Karyakram (JSSK), which included additional services such as support for travel to and from the facility and medical treatment for sick newborn $[17,18]$.

As a consequence of JSY and JSSK, institutional deliveries in India have increased from $40.7 \%$ in 2005-06 to $72.9 \%$ in $2009-10[19,20]$. However, several studies show a persistent and unaccounted high level of outof-pocket expenditure (OOPE) on maternal care (antenatal, delivery and postnatal), similar to expenditure on other public hospital based services [21-23]. The high OOPE is especially catastrophic for poor households, who are often pushed into further poverty and indebtedness on account of this [24-28]. Though some studies have highlighted OOPE for delivery care, there is less attention to explore the components of OOPE during delivery care at public health facilities.

Our objective was to assess the OOPE incurred by rural Indian women while accessing institutional delivery services at public health facilities and to examine components of OOPE. We also assessed the determinants of OOPE and the level of maternal satisfaction with the OOPE on delivery care. For this study, OOPE refers to all the direct expenditure for delivery care including transportation and services availed from private pharmacies and laboratories due to lack of provision at the public health facility.

\section{Methods}

The present analysis is part of a larger study on women's experience of care and their levels of satisfaction with maternal services from secondary health care facilities in India. The study followed a mixed-method design with a literature review and qualitative phase preceding the quantitative phase. The literature review aided in exploring the determinants and themes of care from developing countries [4]. This informed the qualitative phase in which perspectives from both the women and healthcare providers were sought. The quantitative phase consisted of a community survey and focused entirely on women's perspective of delivery care at health facilities. The data presented in this paper is part of the cross-sectional survey. 


\section{Study area}

The community survey was conducted during July August 2014 in two poor performing districts in Uttar Pradesh, one of the high-focus states in India with poor health indicators. The state has high infant mortality rate (50 per 1000 live births) [29], maternal mortality ratio (292 per 100000 live births) and a low percentage of institutional deliveries (45.6\%) [30]. The selected districts had a maternal mortality ratio of 330 . The infant mortality rate was 80 and 82 for the two districts whereas the percent of institutional delivery was 35.2 and 42.4 respectively [30]. The survey was aimed at capturing the experience of women with maternal care from secondary level health facilities. Secondary level health facilities are designated to manage complications with childbirth and have provisions for surgical care, blood transfusion and newborn care. These facilities function as the first referral unit for primary level facilities. There were four functional secondary level health facilities in the two study districts.

\section{Study instrument}

The survey instrument comprised of two parts: the first part was a structured interview schedule capturing women's experience of accessing care from the facility including OOPE on reaching the facility till discharge, and the second part comprised of a scale to assess their satisfaction with care. Based on the literature review and the qualitative study that preceded the survey, items in the instrument were derived from the determinants of structure, process and outcome of care. Among structural determinants, physical environment, cleanliness, availability of human resources, medicines and supplies were included. Determinants of the process of care included interpersonal behavior, privacy, promptness, cognitive care, perceived provider competency and emotional support. Outcome related determinants were the health status of the mother and newborn.

A set of queries focused exclusively on the expenditure across nine categories viz. transportation (hiring vehicle to and from the facility), medicines and supplies (prescribed from the facility), laboratory and diagnostic services, blood transfusion (expenditure for arranging blood), newborn care (in case of neonatal complication, while the mother was still admitted in the facility), expenses on food during her stay in the facility, tips for getting services (in cash or kind: gifts and sweets to facility staff, tips to ambulance driver and facility staff for their services), and other category includes all the expenditure that the women could not classify under the specific categories.

The instrument also included information on socioeconomic status and reproductive history of women. In terms of social profile in India, general caste means the non-vulnerable groups and the vulnerable category includes the backward, scheduled and caste and tribe. The maternal satisfaction scale is a 5 - point Likert scale with ratings ranging from fully satisfied, somewhat satisfied, neither satisfied nor dissatisfied, somewhat dissatisfied and fully dissatisfied. The scale used had 14 items for understanding satisfaction and included items pertaining to structural, technical and interpersonal aspects of care. The study instrument, prepared originally in English, was translated into the local language (Hindi) of the study area. Translation and back translation was carried out to ensure the exactness of meaning of items in the survey instrument and it was pretested among 20 women in a setting similar to that of the study area.

\section{Sampling and data collection}

The study included women who had delivered at the secondary level health facilities and discharged seven to 42 days prior to the interview. Only women with live births were included in the study. A list of the women with their home address who fulfilled the inclusion criteria was collected from the delivery records of the four secondary facilities in the two study districts. The list contained 2130 women, who had given birth between $20^{\text {th }}$ June and $20^{\text {th }}$ July, 2014. The sample size calculated for the study was 550 with $80 \%$ power and $95 \%$ confidence interval. The participants were chosen randomly and the randomization sequence was generated using Excel. A sample of 600 women was selected for survey; oversampling was to address dropouts. There were 10 refusals and 32 women could not be traced due to incorrect address. The dropout rate was seven percent. Total 558 women participated in the study. This included both normal and complicated delivery, and there was no stratification on type of delivery during the sampling. The survey was conducted at women's residences by female researchers who had knowledge of the research topic and local dialect.

\section{Data analysis}

The study refers to OOPE as all the direct expenditure incurred by the women in availing delivery care at the health facility including transportation, all of which are provisioned to be free. This excludes mandatory payments, but includes payment for services from private providers (for transportation, laboratories and pharmacies, etc.) due to shortage or non-functioning of respective services at the public health facility. The costs incurred by relatives or those who accompanied the women were not considered during analysis. Since the women were not aware of all the OOPE related to their deliveries, interviewers sought the help of family members present during the survey to complete the information. Data were collected to calculate direct expenditure only. The 
total expenditure was calculated by adding all the category-wise expenditure mentioned by the respondents. In order to verify the information, cross questions such as "did you pay from your own pocket for medicine" etc. were included in the instrument. Any discrepancy in the data was noted at the site and clarified from the respondents. Since the respondents were unable to distinguish between mandatory fee and others, information on stipulated fees for services was collected from the respective health facilities.

Survey data were analyzed using IBM SPSS version 19. Data analysis included frequencies, Mann-Whitney test (for comparing the difference between the median expenditure of two groups) and categorical regression (to identify the predictors of OOPE where the dependent variable is on numeric scale while independent variables are on nominal \& numeric scales). As the average monthly income and OOPE data were highly skewed, $\log$ transformation was done to make the distribution normal.

\section{Results}

All the women paid a registration cost of one rupee at the health facility and this was not included for analysis as it was a mandatory payment specified by the government. Among the 558 women surveyed for the study, total 540 women paid for one or the other type of services from the public health facilities. Hence the present analysis is confined to the sample size of 540 .

\section{Profile of the respondents}

The characteristics of the respondents are given in Table 1. The mean age of the women was 25 years. Majority of the women were housewives $(98.1 \%)$ and belonged to lower socio-economic strata. For the majority, their husbands were daily wage laborers (43.9\%). Majority women in the sample had a normal vaginal delivery $(93.0 \%)$ and were multi-gravida (64.8\%). A significant proportion of them had to travel more than five kilometers to access the health facility $(79.8 \%)$. On an average, the women stayed at the facility for two days after delivery.

\section{Out of pocket expenditure (OOPE)}

The median OOPE incurred for delivery at the public health facility was INR 700 (US\$ 11.48) (Table 2). There was wide variation in the amount paid and it ranged from INR 15 (US\$ 0.25) to INR 14400 (US\$ 236.07). The women were entitled to receive free transportation to and from the facility; however, in majority of the cases, they had to arrange own transport due to nonresponsiveness of government ambulance service. Even among those who availed the service, it was restricted to one side travel. Hence the total expenditure for transportation varied from INR 20 (US\$ 0.33) to INR
Table 1 Socio-demographic and reproductive profile of respondents $(\mathrm{N}=540)$

\begin{tabular}{|c|c|c|}
\hline Characteristics & & $\begin{array}{l}\text { Respondents, } \\
\mathrm{n}(\%)\end{array}$ \\
\hline Age (years) & Mean (SD) & $24.9(4.01)$ \\
\hline \multirow[t]{3}{*}{ Education of woman } & Illiterate & $259(48.0)$ \\
\hline & Literate & $281(52.0)$ \\
\hline & Mean years of schooling (SD) & $8.4(3.44)$ \\
\hline \multirow[t]{3}{*}{ Religion } & Hindu & $479(88.7)$ \\
\hline & Muslim & $59(10.9)$ \\
\hline & Sikh & $2(0.4)$ \\
\hline \multirow[t]{3}{*}{ Caste } & General & 109 (20.2) \\
\hline & Other backward caste & $232(43.0)$ \\
\hline & $\begin{array}{l}\text { Scheduled caste/scheduled } \\
\text { tribe }\end{array}$ & 199 (36.9) \\
\hline \multirow[t]{2}{*}{ Type of household } & Nuclear & $220(40.7)$ \\
\hline & Joint & $320(59.3)$ \\
\hline \multirow[t]{2}{*}{ Occupation of woman } & Homemaker & $530(98.1)$ \\
\hline & Other work & $10(1.9)$ \\
\hline \multirow[t]{5}{*}{ Occupation of husband } & Cultivator & $149(27.6)$ \\
\hline & Casual labourer & 237 (43.9) \\
\hline & Salaried workers & $59(10.9)$ \\
\hline & $\begin{array}{l}\text { Self-employed in petty trade/ } \\
\text { small scale industry }\end{array}$ & $91(16.9)$ \\
\hline & Unemployed & $4(0.7)$ \\
\hline \multirow{2}{*}{$\begin{array}{l}\text { Average monthly } \\
\text { household income (INR) }\end{array}$} & $\leq 4000$ & $299(55.4)$ \\
\hline & $>4000$ & $241(44.6)$ \\
\hline \multirow[t]{2}{*}{ Gravidity } & 1 & $190(35.2)$ \\
\hline & 2 or more & $350(64.8)$ \\
\hline \multirow[t]{2}{*}{ Delivery } & Normal vaginal & $502(93.0)$ \\
\hline & C-section \& breech & $38(7.0)$ \\
\hline Duration of stay (days) & Mean (SD) & $2.1(1.7)$ \\
\hline \multirow[t]{2}{*}{ Distance to health facility } & Upto 5 km & 109 (20.2) \\
\hline & More than $5 \mathrm{~km}$ & $431(79.8)$ \\
\hline
\end{tabular}

${ }^{a}$ Median income is INR 4000

1634 (US\$ 26.79) with a median expenditure of INR 142.5 (US\$ 2.34). Expenditure for newborn care, if he/ she was referred to a private facility, ranged from INR $100-2000$ (US\$1.64 - 32.79) depending on the nature of complication. More than half of the women spent on medicines, cotton pads, syringes and saline, which they bought from private pharmacies. The laboratory facility was not functional round the clock, leading to users relying on private laboratories in the vicinity of the hospital. Tips for getting services, which $86 \%$ of women had to incur, included tips to avail government ambulance, and bribes either in cash or kind (for example, distributing sweets) to facility staff for their services. Overcrowding in the facility led to women paying the 
Table 2 Item-wise expenditure for delivery care $(N=540)$

\begin{tabular}{llll}
\hline Items $(n)$ & \multicolumn{2}{l}{ Median expenditure in INR (min-max) } \\
\cline { 2 - 4 } & Normal $(n=461)$ & Complicated $(n=79)$ & Total (N=540) \\
\hline Transportation $(n=458)$ & $130(20-1500)$ & $150(20-1634)$ & $142.5(20-1634)$ \\
Medicines and supplies $(n=298)$ & $100(15-1200)$ & $110(35-8000)$ & $100(15-8000)$ \\
Laboratory investigations $(n=13)$ & $20(10-200)$ & $450(100-1700)$ & $100(10-1700)$ \\
Blood transfusion $(n=2)$ & - & $500(500-500)$ & $500(500-500)$ \\
Newborn care in private facility $(n=3)$ & $a$ & a & $200(100-2000)$ \\
Tips for getting services $(n=466)$ & $300(10-2000)$ & $400(20-7000)$ & $320(10-7000)$ \\
Food (from the facility) $(n=15)$ & $200(20-500)$ & $225(30-500)$ & $200(20-500)$ \\
Any other $(n=265)$ & $300(20-3000)$ & $400(20-6000)$ & $300(20-6000)$ \\
Total expenditure $(n=540)$ & $680(15-5200)$ & $970(20-14400)$ & $700(15-14400)$ \\
\hline
\end{tabular}

${ }^{a}$ Number of cases are not enough to calculate median as they are divided between normal (1) and complicated (2) categories US\$ $1=61$ INR

staff for obtaining a bed in the antenatal and postnatal care wards.

The classification of 'normal' refers to normal vaginal delivery, and 'complicated' indicates all the caesarian and breech deliveries along with maternal complications post-delivery. There was a noticeable difference in the expenditure incurred for normal and complicated cases. Complicated cases had higher OOPE for most of the items compared to normal cases. The difference was striking for laboratory investigations with median INR 450 (US\$ 7.38) for complicated cases and only INR 20 (US\$ 0.33) for normal cases.

\section{Determinants of OOPE}

Table 3 presents the total OOPE against selected socioeconomic and reproductive variables. The significant variables were caste, income, gravidity, type of delivery, and presence of Accredited Social Health Activist (ASHA). The OOPE for other castes was higher than the vulnerable groups of 'other backward caste, scheduled caste/tribe' taken together. Similarly, those in the higher income group (above INR 4000 per month) paid more compared to lower income group. The OOPE for multi-gravida was less compared to primi-gravida. The complications associated with delivery (such as C-section and breech cases as well as health complications of mother soon after delivery) incurred higher OOPE than normal delivery. Presence of ASHA during delivery led to less OOPE as the median expenditure was INR 680 compared to INR 980 for the women when ASHA was not present.

Regression analysis for OOPE provided three significant predictors for OOPE viz. caste, type of delivery and presence of ASHA during delivery (Table 4).

\section{Level of maternal satisfaction with OOPE}

Level of satisfaction with delivery care at the secondary level public health facilities was assessed using the
Maternal Satisfaction Scale (Table 5). Out of pocket expenditure was one of the least satisfied items marked by the women. Only three percent women were fully satisfied with it. Similarly, the dissatisfaction score was strikingly high with $18.7 \%$ which was the second highest among the enquired items.

\section{Discussion}

The study estimated the OOPE incurred by rural Indian women while accessing institutional delivery services at secondary level public health facilities and also examined

Table 3 Total expenditure for care across selected variables $(N=540)$

\begin{tabular}{|c|c|c|}
\hline Variable & & Median expenditure in INR (IQR) \\
\hline \multirow[t]{2}{*}{ Age (Years) } & $<25$ & $680(520)$ \\
\hline & $\geq 25$ & $740(665)$ \\
\hline \multirow[t]{2}{*}{ Education of woman } & Illiterate & $670(510)$ \\
\hline & Literate & $730(600)$ \\
\hline \multirow[t]{2}{*}{ Religion } & Hindu & $700(550)$ \\
\hline & Non-Hindu & $600(540)$ \\
\hline \multirow[t]{2}{*}{ Caste $e^{* * *}$} & General & $850(780)$ \\
\hline & $\mathrm{OBC}, \mathrm{SC} / \mathrm{ST}$ & $670(535)$ \\
\hline \multirow[t]{2}{*}{ Income $(\mathrm{INR})^{* *}$} & $\leq 4000$ & $620(520)$ \\
\hline & $>4000$ & $750(550)$ \\
\hline \multirow[t]{2}{*}{ Gravida** } & Primi & 785 (678) \\
\hline & Multi & $660(495)$ \\
\hline \multirow[t]{2}{*}{ Sex of baby } & Female & $655(493)$ \\
\hline & Male & $720(569)$ \\
\hline \multirow[t]{2}{*}{ Type of delivery*** } & Normal & $680(510)$ \\
\hline & Complicated & $970(1050)$ \\
\hline \multirow[t]{2}{*}{ Presence of $\mathrm{ASHA}^{* * *}$} & Yes & $680(510)$ \\
\hline & No & $980(1675)$ \\
\hline
\end{tabular}

${ }^{* *} p<0.01,{ }^{* * *} p<0.001$

Significance level is determined using Mann- Whitney test US\$ $1=61$ INR 
Table 4 Categorical regression for OOPE

\begin{tabular}{|c|c|c|c|}
\hline Variable & & Standardized Beta & Standard error \\
\hline \multirow[t]{2}{*}{ Age (Years) } & $<25$ & & 0.035 \\
\hline & $\geq 25$ & 0.016 & \\
\hline \multirow[t]{2}{*}{ Education } & Illiterate & & 0.025 \\
\hline & Literate & 0.011 & \\
\hline \multirow[t]{2}{*}{ Religion } & Hindu & 0.052 & 0.034 \\
\hline & Non-Hindu & & \\
\hline \multirow[t]{2}{*}{ Caste $^{*}$} & General & 0.098 & 0.041 \\
\hline & $\mathrm{OBC}, \mathrm{SC} / \mathrm{ST}$ & & \\
\hline Income (INR) ${ }^{\mathrm{a}}$ & & 0.025 & 0.043 \\
\hline \multirow[t]{2}{*}{ Gravida } & Primi & & 0.047 \\
\hline & Multi & 0.065 & \\
\hline \multirow[t]{2}{*}{ Sex of baby } & Female & & 0.024 \\
\hline & Male & 0.002 & \\
\hline \multirow[t]{2}{*}{ Type of delivery*** } & Normal & & 0.060 \\
\hline & Complicated & 0.199 & \\
\hline \multirow[t]{2}{*}{ Presence of $\mathrm{ASHA}^{*}$} & Yes & & 0.049 \\
\hline & No & 0.103 & \\
\hline
\end{tabular}

${ }^{*} p<0.05,{ }^{* * *} p<0.001$

${ }^{a}$ Natural log of income has taken

its item-wise composition. The study revealed that the services from the government health facility were not free for the women. The OOPE varied from INR 680 to 970 (US\$ 11.15 - 15.90) depending on delivery complications. The major component of OOPE was tips for getting services, which comprised of tips for services and gifts in cash or kind. Women from higher income group, general caste, primi-gravida and those without ASHAs paid more compared to their counterparts.

Similar findings have been highlighted in several other studies in which they discussed the high OOPE for institutional delivery in India [28, 31-34]. Recent national level statistics in India revealed that rural population spent on an average INR1587 (US\$ 26.0) and urban population INR 2117 (US\$ 34.7) to deliver at public facilities [35]. Similar observations were made from other developing countries also. For instance, a study from Bangladesh reported the expenditure for services at government health facilities to be US\$ 31.9 for a normal delivery and US\$ 117.5 for a caesarean delivery [36]. The median OOPE calculated in the present study was INR 700 (US\$ 11.48) with wide variation between normal (INR 680 - US\$ 11.15) and complicated cases (INR 970 (US\$ 15.90). Based on the data from district level household survey, the estimated mean OOPE for delivery in public health facilities in India is US\$ 39 [32]. They found that the OOPE for $\mathrm{C}$-section delivery is six times higher than that for normal vaginal delivery. With the same data, another study showed that median OOPE in public health facilities is INR 1000 (US\$ 16.39) and INR 4045 (US\$ 66.31) for normal and caesarian deliveries respectively [28]. A study in Uttar Pradesh also found that families pay between INR 500 and 700 (US\$ 8.20 - 11.48) to hospital staff at the time of admission or when they have a newborn [22]. The OOPE became

Table 5 Maternal satisfaction with delivery care $(N=540)$

\begin{tabular}{|c|c|c|c|c|c|}
\hline \multirow[t]{2}{*}{ Item } & \multicolumn{5}{|c|}{ Level of satisfaction (\%) } \\
\hline & Fully satisfied & Somewhat satisfied & Neither satisfied nor dissatisfied & Somewhat dissatisfied & Fully dissatisfied \\
\hline Lack of physical abuse & 23.0 & 1.0 & 1.3 & 0.4 & 1.0 \\
\hline Privacy inside labour room & 15.9 & 10.6 & 4.3 & 1.0 & 0.4 \\
\hline Cleanliness of labour room & 13.3 & 12.9 & 5.1 & 1.5 & 1.0 \\
\hline Comfort of bedding & 8.9 & 13.2 & 8.7 & 3.7 & 1.7 \\
\hline Information on progression of labour & 8.7 & 12.1 & 6.4 & 5.1 & 3.8 \\
\hline Waiting time & 6.5 & 7.7 & 12.6 & 5.2 & 4.0 \\
\hline Timely availability of medicine & 6.2 & 9.6 & 7.6 & 11.8 & 2.9 \\
\hline Care and sympathy in labour room & 4.2 & 10.1 & 14.9 & 6.2 & 2.4 \\
\hline Pain relief & 3.4 & 7.4 & 13.5 & 9.8 & 4.0 \\
\hline \multirow[t]{2}{*}{ Out of pocket expenditure } & 3.0 & 2.4 & 2.6 & 9.0 & 18.7 \\
\hline & ${ }^{\mathrm{a}} 11.9$ & 5.0 & 7.2 & 19.1 & 56.9 \\
\hline Advise on breastfeeding & 2.6 & 4.3 & 3.8 & 14.1 & 13.2 \\
\hline Health advice on cord care & 2.0 & 2.0 & 2.8 & 11.3 & 18.5 \\
\hline Health check-up soon after delivery & 1.6 & 2.4 & 3.3 & 10.2 & 19.1 \\
\hline Opportunity to clarify health concern & 0.8 & 4.2 & 13.3 & 10.6 & 9.2 \\
\hline Total & 100 & 100 & 100 & 100 & 100 \\
\hline
\end{tabular}

${ }^{\mathrm{a}}$ Row-wise per cent 
catastrophic to families as it surpasses the JSY incentive (INR 1400) in several instances. A study from Orissa highlighted that the JSY incentive accounted to only $25.5 \%$ of total maternal expense in rural and $14.3 \%$ in urban areas [31].

However, large data sets do not generally allow any detailing to understand the areas where women are paying more. Therefore, the detailed analysis requires in-depth studies utilizing the strengths of mixed methods, like the present study. The major component in OOPE was tips for getting services which include buying gifts to facility staff and tips for services. The median of tips for getting services was INR 320 (US\$ 5.25) with a wide range of INR 10 - 7000 (US\$ 0.16 - 114.75). The OOPE for complicated cases was higher due to the need for specialized services. In such cases women had to pay for medicines and supplies, laboratory and diagnostic services, blood transfusion and newborn care in private facilities as these services were not fully functional at the public health facilities. A few other studies also reported similar findings and they highlighted how the hospital staff sent family members to nearby private medical shops to buy intramuscular injections of oxytocin and epidosin to speed delivery and also to private diagnostic clinics to conduct ultrasound test [37, 38].

There is difference in OOPE based on sociodemographic characteristics. Those from the general caste and higher income group paid more compared to backward castes and lower income group. In addition to this, the OOPE for primi-gravida was higher than that of multi-gravida. A study from Bulgaria on informal payment in health facilities also found that wealthier, better educated, younger respondents tend to pay more for obtaining better-quality treatment [39]. Studies from India also reported that mean OOPE on delivery was found to be higher among women with higher education and those belonging to a higher wealth quintile, as they have the ability to pay for better quality of service [28-32].

One of the key aspects of promoting institutional delivery, is the role of community health worker- ASHA, in not only motivating the woman to deliver at a health facility but also to accompany her and stay during the entire delivery process [15]. Being familiar with the health system, she is an important link between the community and the health services. The main reason for her to accompany the woman is to inform the woman about the services she is entitled for and also provide emotional support in an unfamiliar environment. In spite of her presence, the study showed that women had incurred OOPE, though it was less when the ASHA was present during delivery care. In some of our qualitative interviews, the ASHAs in fact negotiated with the facility staff in aiding women to avail timely services [40]. There are studies that have highlighted how ASHAs are used by hospital staff to facilitate tips for getting services, and being lower in the health system hierarchy, how they are compelled to negotiate such transaction [22].

The OOPE was among the items rated the least satisfactory on the maternal satisfaction scale. Among the respondents, $76 \%$ were dissatisfied (both somewhat dissatisfied and fully dissatisfied) with the payments they made while accessing care at the facility. The remaining $24 \%$ included those who were satisfied (both somewhat satisfied and fully satisfied) and also who did not have any particular opinion about the expenditure. The low level of satisfaction with expenditure while accessing healthcare is reported in other studies also [41]. Some studies have reported that attitude to tips for getting services varies from strongly negative to tolerant depending on whether the payment is solicited by the facility staff or offered by the users themselves [39]. Evidence from large-scale population-based surveys in India highlighted the issue of non-utilization of maternal health services due to the cost [42]. As women can evaluate and express their satisfaction with regard to expenditure related to their care, it has implications on utilization of public health facilities for delivery in the future.

\section{Limitations}

The major limitation with the study was the recall bias in reporting the exact expenditure for delivery care at the health facility. In most instances, the male member or the older women who accompanied the pregnant women handled the monetary aspects. Hence, responses from other family members were also recorded. Another difficulty was the inability of some respondents to distinguish between official and unofficial payments. This was clarified with the help of information collected from the respective health facilities on official fees.

\section{Conclusions}

The study highlighted that the services from the public health facilities for delivery care, which were supposed to be free as per safe delivery program of the government, were in fact not free. The women had to incur high OOPE, which varied according to complications associated with the delivery. The item-wise analysis revealed that the major component of OOPE was tips for getting services, followed by expenditure for purchasing medicine, supplies and diagnostic care, which were otherwise mandated to be provided by the health facilities. The findings emphasize the need for a mechanism to curtail tips for services and to improve the availability of medicine and supplies, laboratory and diagnostic services and provision of food from the facility. Though the presence of ASHA helped in reducing the OOPE, they could not eliminate it. There is limited evidence on the areas where women have to incur OOPE within 
health facilities, which calls for further studies in different geographic locations, to understand the nature and prevalence of OOPE. The very purpose of conditional cash transfer scheme will be lost if a woman has to pay almost half of the monetary incentive in accessing services that are supposed to be free of cost. OOPE on accessing care at public health facilities is one of the key determinants of service utilization, and if not addressed by the health system, can deter women from delivering in public health facilities in future in spite of the cash incentive scheme.

\section{Endnotes}

${ }^{1}$ One US\$ $=61$ INR (during the time of field work -2014)

\section{Acknowledgements}

We acknowledge the technical guidance and input provided by Dr. Bilal Avan of London School of Hygiene and Tropical Medicine in conceptualizing the study, instrument development and analysis. Dr. Arpita Ghosh of Public Health Foundation of India provided inputs during data analysis.

\section{Funding}

The study was supported by the Wellcome Trust Capacity Strengthening Strategic Award to the Public Health Foundation of India and a consortium of United Kingdom universities.

\section{Availability of data and materials}

The data are available from the authors upon request.

\section{Authors' contributions}

Al carried out data collection, analyzed the data and drafted the manuscript. SC contributed towards study design, analysis and revision of the manuscript. AS reviewed the literature and contributed in drafting and reviewing the manuscript. SB conceptualized and designed the study, provided overall guidance and reviewed the manuscript. All authors have read and approved the final manuscript.

\section{Competing interests}

The authors declare that they have no competing interests.

\section{Consent for publication}

Not applicable.

\section{Ethics approval and consent to participate}

Ethical approval for this study was granted by the Institutional Ethics Committee of the Public Health Foundation of India (TRC-IEC-187/13). A written permission from district Chief Medical Officer was obtained and the cooperation from head of respective secondary level health facilities was sought. The purpose of the study was explained and verbal consent was sought from women. Anonymity of identity and confidentiality of information was assured to all the participants during analysis.

Received: 4 March 2016 Accepted: 18 August 2016

Published online: 24 August 2016

\section{References}

1. World Health Organization, UNICEF, UNFPA and The World Bank. Trends in Maternal Mortality: 1990-2010. WHO, UNICEF, UNFPA and The World Bank estimates. Geneva: World Health Organization; 2012.

2. United Nations Children's Fund. The State of the World's Children, 2009: Maternal and Newborn Health. New York: United Nations Children's Fund; 2008.

3. Jehan K, Sidney K, Smith H, de Costa A. Improving access to maternity services: an overview of cash transfer and voucher schemes in South Asia. Reprod Health Matters. 2012;20(39):142-54.

4. Srivastava A, Avan Bl, Rajbangshi P, Bhattacharyya S. Determinants of women's satisfaction with maternal health care: a review of literature from developing countries. BMC Pregnancy Childbirth. 2015;15:97. doi:10.1186/ s12884-015-0525-0.

5. Skordis-Worrall J, Pace N, Bapat U, Das S, More NS, Joshi W. Maternal and neonatal health expenditure in Mumbai slum (India): A cross sectional study. BMC Public Health. 2011;11:150. doi:10.1186/1471-2458-11-150.

6. Mackeith N, Chinganya OJM, Ahmed Y, Murray SF. Zambian women's experiences of urban maternity care: results from a community survey in Lusaka. Afr J Reprod Health. 2003;7:92-102.

7. Cham M, Sundby J, Vangen S. Availability and quality of emergency obstetric care in Gambia's main referral hospital: women-users' testimonies. Reprod Health. 2009;6:5. doi:10.1186/1742-4755-6-5.

8. D'Ambruoso L, Abbey M, Hussein J. Please understand when I cry out in pain: women's accounts of maternity services during labour and delivery in Ghana. BMC Public Health. 2005;5:140.

9. George A. Quality of reproductive care in private hospitals in Andhra Pradesh: Women's perception. Econ Political Wkly. 2002;37:1686-92.

10. Ohagwu CC, Abu PO, Odo MC, Chiegwu HU. Maternal perception of barriers to utilization of prenatal ultrasound in prenatal care in the northern part of Nigeria. Clin Mother Child Health. 2010;7:1195-9.

11. Bazant ES, Koenig MA. Women's satisfaction with delivery care in Nairobi's informal settlements. Int J Qual Health Care. 2009;21:79-86.

12. Aniebue UU, Aniebue PN. Women's perception as a barrier to focused antenatal care in Nigeria: the issue of fewer antenatal visits. Health Policy Plan. 2011;26:423-8.

13. El-Mohimen HAA, Abd-Rabou RA, Ali HA, Tosson MM. Evaluation of ANC services \& women's perception in Assiut University Hospital. Ass Univ Bull Environ Res. 2006;9:31-40,

14. Registrar General of India. Special bulletin on maternal mortality in India 2010-12. New Delhi: Government of India; 2013.

15. Government of India (Gol). Janani Suraksha Yojana. New Delhi: Ministry of Health and Family Welfare; 2006. http://mohfw.nic.in/WriteReadData/l892s/ file28-99526408.pdf.

16. Randive B, Diwan V, de Costa A. India's conditional cash transfer programme (the JSY) to promote institutional birth: is there an association between institutional birth proportion and maternal mortality? PLoS One. 2013;8(6):e67452. doi:10.1371/journal.pone.0067452.

17. Ministry of Health and Family Welfare, Government of India: National health policy 2015 draft. 2014. http://www.mohfw.nic.in/showfile.php?lid=3014

18. Ministry of Health and Family Welfare, Government of India: Executive Summary of NRHM programme. 2012. http://www.mohfw.nic.in/ WriteReadData/1892s/4ExecutiveSummary.pdf.

19. Indian Institute for Population Sciences (IIPS) and Macro International. National family health survey (NFHS 3) 2005-06 - India, Volume I. Mumbai: IIPS; 2007.

20. United Nations children's Fund (UNICEF). Coverage evaluation survey. National factsheet. New Delhi: UNICEF; 2009.

21. Leone T, James KS, Padmadas SS. The burden of maternal health care expenditure in India: multilevel analysis of national data. Matern Child Health J. 2013;17(9):1622-30. doi:10.1007/s10995-012-1174-9.

22. Coffey D. Costs and consequences of a cash transfer for hospital births in a rural district of Uttar Pradesh. India Soc Sci Med. 2014;114:89-96.

23. Tripathi N, Saini SK, Prinja S. Impact of Janani Shishu Suraksha Karyakram on out-of-pocket expenditure among urban slum dwellers in Northern India. Indian Pediatrics. 2014;51:475-77.

24. Bonu S, Bhushan I, Rani M, Anderson I. Incidence and correlates of 'catastrophic' maternal health care expenditure in India. Health Policy Plan. 2009;2(6):445-56.

25. Dilip TR. Utilization of inpatient care from private hospitals: trends emerging from Kerala India. Health Policy Plan. 2010;25(5):437-46.

26. Garg C, Karan A. Reducing out-of-pocket expenditures to reduce poverty: a disaggregated analysis at rural-urban and state level in India. Health Policy Plan. 2009;24(2):116-28.

27. Mukherjee S, Singh A, Chandra R. Maternity or catastrophe: a study of household expenditure on maternal health care in India. Health. 2013;5(1): 109-18.

28. Modugu HR, Kumar M, Kumar A, Christopher M. State and sociodemographic group variation in out-of-pocket expenditure, borrowings and Janani Suraksha Yojana (JSY) programme use for deliveries in India. BMC Public Health. 2012;12:1048.

29. Registrar General of India. Sample registration system bulletin. New Delhi: Government of India. 2014;49:1. 
30. Registrar General of India. Annual health survey (AHS) in 8 EAG states and Assam 2010-11. New Delhi: Government of India; 2012.

31. Gopalan SS, Durairaj V. Addressing maternal healthcare through demand side financial incentives: Experience of Janani Suraksha Yojana program in India. BMC Health Services Research. 2012;12:319.

32. Mohanty KS, Srivastava A: Out-of-pocket expenditure on institutional delivery in India. Health Policy Plan 2012; doi:10.1093/heapol/czs057

33. Shrestha B, Paneru DP, Shrestha N, Dhimal B. Client's satisfaction on maternity services at Paropakar maternity and women's hospital, Kathmandu. Online J Health Allied Scs. 2010;1(1):56-9.

34. Dhar RSG, Nagpal J, Sinha S, Bhargava VL, Sachdeva A, Bhartia A. Direct cost of maternity-care services in South Delhi: a community survey. J Health Popul Nutr. 2009;27:368-78.

35. National Sample Survey Organization (NSSO). Key Indicators of Social Consumption in India - Health. Report No. NSS KI (71/25.0). New Delhi: Ministry of Statistics and Program Implementation; 2015.

36. Borghi J, Sabina N, Blum LS, Hoque ME, Ronsmans C. Household costs of healthcare during pregnancy, delivery, and the postpartum period: a case study from Matlab. Bangladesh J Health Popul Nutr. 2006;24:446-55.

37. Jeffery P, Das A, Dasgupta J, Jeffery R. Unmonitored intrapartum oxytocin use in home deliveries: evidence from Uttar Pradesh India. Reprod Health Matters. 2007:15(30):172-8.

38. Gupta SK, Pal DK, Tiwari R, Garg R, Sarawagi R, Shrivastava KA, Gupta P. Assessment of Janani Suraksha Yojana (JSY) - in Jabalpur, Madhya Pradesh: knowledge, attitude and utilization pattern of beneficiaries: a descriptive study. Int J Biol Med Res. 2011:1(2):06-11.

39. Balabanova D, McKee M. Understanding informal payments for health care: the example of Bulgaria. Health Policy. 2002;62(3):243-73.

40. Bhattacharyya S, Issac A, Rajbangshi P, Srivastava A, Avan BI. User's perspective to improve quality in maternal health care: development of maternal satisfaction scale for secondary level of care. Report. New Delhi: Public Health Foundation of India; 2015.

41. Emelumadu OF, Onyeonoro UU, Ukegbu AU, Ezeama NN, Ifeadike CO, Okezie OK. Perception of quality of maternal healthcare services among women utilizing antenatal services in selected primary health facilities in Anambra State, Southeast Nigeria. Niger Med J. 2014;55:148-55.

42. Indian Institute for Population Sciences (IIPS). District Level Household and Facility Survey (DLHS-3), 2007-08. Mumbai: IIPS; 2010

\section{Submit your next manuscript to BioMed Central and we will help you at every step:}

- We accept pre-submission inquiries

- Our selector tool helps you to find the most relevant journal

- We provide round the clock customer support

- Convenient online submission

- Thorough peer review

- Inclusion in PubMed and all major indexing services

- Maximum visibility for your research

Submit your manuscript at www.biomedcentral.com/submit

C Biomed Central 